\title{
The Ethical Evaluation of Animal Experiments Deserves More Than Empty Phrases
}

\author{
Tilo Weber \\ Animal Welfare Academy, German Animal Welfare Federation, Neubiberg, Germany
}

Recently, we have been engaged with issues of transparency of experiments involving the use of animals (Taylor et al., 2018). While researching for the paper, we repeatedly noticed references to generic statements provided by interest groups who support the use of experimental animals to describe the benefits of the proposed animal research.

There is a clear public demand for the highest level of transparency possible for experiments involving animals. This demand was enshrined in European Directive 2010/63/EU on the protection of animals used for scientific purposes (EU, 2010). Recital clause 41 states that to "ensure that the public is informed, it is important that objective information concerning projects using live animals is made publicly available". This was implemented as a requirement to provide a non-technical summary (NTS) in every application for authorisation of a project involving animal experiments. EU member states must make these NTS publicly available upon authorisation of the projects. According to Article 43 , NTS shall provide, amongst other things, "information on the objectives of the project, including the predicted harm and benefits".

The official guidance document requires that the benefits section of an NTS states the potential benefits likely to derive from the animal research project (EC, 2013). This can include which scientific questions may be answered, which scientific progress may be supported and how humans and animals may benefit from the project (BfR, 2013). The information given in the NTS should be as detailed as possible, because recital clause 39 of the Directive states that it "is also essential, both on moral and scientific grounds, to ensure that each use of an animal is carefully evaluated as to the scientific or educational validity, usefulness and relevance of the expected result of that use. The likely harm to the animal should be balanced against the expected benefits of the project".

Therefore, using general statements or referring to generic statements provided by third parties to explain the (potential) benefit in order to replace the obligatory ethical evaluation of the project with thought-terminating clichés is ethically problematic, irresponsible, and in breach of the guidance.

This strategy suggests to the layperson that animal experiments are justified a priori, a trend we are now witnessing in Germany, right under the eyes of the regulatory authorities.

\section{References to biased information in the NTS}

All NTS authorised by the regulatory authorities in Germany since 2013 are uploaded to the database AnimalTestInfo ${ }^{1}$. In September 2018 we performed database searches for the names of associations that we consider to provide biased information on animal experiments. We searched for the key words "pro-test", "speakingofresearch", and "tierversuche-verstehen" and found several NTS containing at least one of these key words ${ }^{2}$. In all hits, the key word(s) appear(s) only in the "benefits" section of the NTS. The publication dates ranged from 2015 to 2018 and indicate increasing use.

The benefits sections of ID 15150 and 17264 end with the sentence "General information on the benefit of animal experiments:"3, before citing the websites "Tierversuche verstehen" and "Pro-Test Deutschland". Five NTS (ID 8370; 9058; 17292; 20102; 20151) contain "General information on animal experiments:"3, before citing the websites "Speaking of Research" and "Pro-Test Deutschland"; ID 9472 contains the same phrase but cites only the website "Pro-Test Deutschland".

\section{Advocating pro-animal research}

Thus, even though the benefit section of NTS should present the specific potential benefits likely to derive from the proposed project, applicants are closing their explanation with references to websites of external associations where general information on (the benefits) of animal experiments can be found. Even more alarming is the fact that the referred associations provide biased, subjective information and are backed by institutes and organisations that are known to advocate animal research indiscriminately.

\footnotetext{
1 https://www.animaltestinfo.de/

2 The key word „pro-test“ was found in the NTS 8370; 9058; 9472; 15150; 17264; 17292; 20102 and 20151; "speakingofresearch" in 8370; 9058 ;

17292; 20102 and 20151 and "tierversuche-verstehen" in 15150 and 17264 (IDs from AnimalTestlnfo).

3 Translated from German by the author
}

Received October 4, 2018; Accepted October 8, 2018; (c) The Author, 2018.

ALTEX 35(4), 518-519. doi:10.14573/altex.1810041

Correspondence: Tilo Weber, German Animal Welfare Federation, Animal Welfare Academy, Spechtstr. 1, 85579 Neubiberg, Germany (tilo.weber@tierschutzakademie.de)
This is an Open Access article distributed under the terms of the Creative Commons Attribution 4.0 International license (http://creativecommons.org/licenses/by/4.0/) which permits unrestricted use, distribution and reproduction in any medium, provided the original work is appropriately cited. 
"Pro-Test Deutschland" declares on its website that "an overwhelming majority of the public doesn't want to and cannot abstain from the merits of animal research" 3,4 . This German association follows the example of the British "Pro-Test" 5 until it closed down in 2011 and its US-based sister organisation "Speaking of Research"6 expanded its activities into the UK.

"Speaking of Research" defines itself as "an international advocacy group that provides accurate information about the importance of animal research" and is "run by a committee of people who believe that animal research remains crucial to the future of medicine"'.

"Tierversuche verstehen" asserts that it provides "insights into the need for responsible animal experiments" 3,7 , although it is coordinated by an alliance of several science and research organizations in Germany, including institutes that perform animal experiments themselves. Clearly, neutral, objective information on animal experiments cannot be expected from these associations.

\section{An ethical evaluation demands specific, not generic information}

As demanded in the Directive and the respective national legislation of the member states concerning the use of animals for scientific purposes, a project should only be authorised if it has undergone a thorough ethical evaluation and the expected benefit clearly outweighs the potential harm that is going to be inflicted on the animals.

However, there is a special situation with regard to the ethical evaluation of animal experiments in Germany. Since a court order by the Federal Administrative Court of Germany became final in $2014^{8}$, German competent authorities are no longer allowed to question the ethical evaluation submitted by applicants nor to perform independent evaluations. Therefore, the applicants themselves are expected to comprehensively address the possible harms inflicted on the animals and weigh them against the potential benefits of their project. This is absurd since the applicants obviously have a conflict of interest: the interest to perform their project to further their career $v s$. the obligation to ethically evaluate their project. It is unlikely that an applicant would conclude that his/her experiment is ethically unjustified.

As understandable as being lazy about the evaluation is under the legal circumstances, it should be understood that referring to general information on the benefits of animal experiments or potentially even replacing the detailed description of the benefits of a project with generic citations is clearly in breach of the provision of recital clause 39 in the Directive (see above). Especially, the description of the potential benefits included in the NTS is important to enable the public to independently draw a personal conclusion whether they consider the authorized animal experiments to be ethically justified.

We therefore strongly encourage researchers who apply for authorisation of projects involving animals to take their responsibility seriously and strive to question - each and every time anew - whether the use of animals is ethically justified to answer their research questions as is their ethical and legal obligation. We also encourage competent authorities to thoroughly evaluate the quality and completeness of the NTS presented by applicants, especially in terms of the information on harms and benefits. They should reject references to general and generic statements in NTS and demand the insertion of a detailed, project-specific evaluation to allow an objective and neutral ethical evaluation. In addition, the Federal Institute for Risk Assessment (Bundesinstitut für Risikobewertung, BfR) as the national authority commissioned by the German legislator to publish the NTS should check every NTS received from regulatory authorities before uploading it to AnimalTestInfo and return inappropriate NTS to the regulatory authorities for revision and correction.

\section{References}

BfR (2013). Leitfaden zur Erstellung der Nichttechnischen Projektzusammenfassung (NTP) für Tierversuchsvorhaben, Version 1.2. https://bit.ly/2OOOcC4

EC - European Commission (2013). National Competent Authorities for the implementation of Directive 2010/63/EU on the protection of animals used for scientific purposes. Working document on Non-Technical Project summaries. https://bit. 1y/2E5Cf6V

EU - European Union (2010). Directive 2010/63/EU of the European Parliament and the Council of 22 September 2010 on the protection of animals used for scientific purposes. $O J L$ 276, 33-79. https://bit.ly/2QAmUN0

Taylor, K., Rego, L. and Weber, T. (2018). Recommendations to improve the EU non-technical summaries of animal experiments. ALTEX 35, 193-210. doi:10.14573/altex.1708111

\footnotetext{
4 http://www.pro-test-deutschland.de/ueber-uns/mission/ accessed in October 2018

5 http://www.pro-test.org.uk/ accessed in October 2018

$6 \mathrm{https}: / /$ speakingofresearch.com/about/ accessed in October 2018

$7 \mathrm{https}: / /$ www.tierversuche-verstehen.de/ueber-uns/ accessed in October 2018

8 Federal Administrative Court of Germany, court order from 20.01.2014 - 3 B 29.13
} 